\title{
Insulin glargine and risk of cancer: a cohort study in the French National Healthcare Insurance Database
}

\author{
P. Blin • R. Lassalle $\cdot$ C. Dureau-Pournin • \\ B. Ambrosino - M. A. Bernard - A. Abouelfath • \\ H. Gin • C. Le Jeunne • A. Pariente • C. Droz • N. Moore
}

Received: 6 June 2011 / Accepted: 2 December 2011 / Published online: 6 January 2012

(C) The Author(s) 2012. This article is published with open access at Springerlink.com

\begin{abstract}
Aims/hypothesis Using the Echantillon Généraliste de Bénéficiaires: random 1/97 permanent sample of the French national healthcare insurance system database (EGB), we investigated whether, as previously suspected, the risk of cancer in insulin glargine (A21Gly,B31Arg,B32Arg human insulin) users is higher than in human insulin users. The investigation period was from 1 January 2003 to 30 June 2010.
\end{abstract}

\footnotetext{
P. Blin • R. Lassalle $\cdot$ C. Dureau-Pournin • B. Ambrosino M. A. Bernard - A. Abouelfath $\cdot$ A. Pariente $\cdot$ C. Droz $\cdot$ N. Moore $(\bowtie)$

Department of Pharmacology, Bat du Tondu, Case 40, Université de Bordeaux,

146 Rue Léo Saignat,

33076 Bordeaux, France

e-mail: nicholas.moore@pharmaco.u-bordeaux2.fr

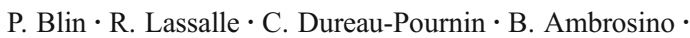
M. A. Bernard $\cdot$ A. Abouelfath $\cdot$ A. Pariente $\cdot$ C. Droz $\cdot$ N. Moore Inserm CIC-P0005,

Bordeaux, France

H. Gin $\cdot$ A. Pariente $\cdot$ N. Moore

CHU de Bordeaux,

Bordeaux, France

H. Gin

Université Bordeaux Segalen,

Bordeaux, France

C. Le Jeunne

Hotel-Dieu,

Paris, France

A. Pariente $\cdot$ C. Droz $\cdot$ N. Moore

Inserm U657,

Bordeaux, France

Methods We used Cox proportional hazards time-dependent models that were stratified on propensity score quartiles for use of insulin glargine vs human insulin, and adjusted for insulin, biguanide and sulfonylurea possession rates to assess the risk of cancer or death in all or incident exclusive or predominant ( $\geq 80 \%$ use time) users of insulin glargine compared with equivalent human insulin users.

Results Only type 2 diabetic patients were studied. Exposure rates varied from 2,273 and 614 patient-years for incident exclusive users of insulin glargine or human insulin, respectively, to 3125 and 2341 patient-years for all patients predominantly using insulin glargine or human insulin, respectively. All-type cancer HRs with insulin glargine vs human insulin ranged from $0.59(95 \%$ CI $0.28,1.25)$ in incident exclusive users to $0.58(95 \% \mathrm{CI} 0.34,1.01)$ in all predominant users. Cancer risk increased with exposure to insulin or sulfonylureas in these patients. Adjusted HRs for death or cancer associated with insulin glargine compared with human insulin ranged from $0.58(95 \%$ CI $0.32,1.06)$ to 0.56 (95\% CI 0.36 , 0.87).

Conclusions/interpretation There was no excess risk of cancer in type 2 diabetic patients on insulin glargine alone compared with those on human insulin alone. The overall risk of death or cancer in patients on insulin glargine was about half that of patients on human insulin, thereby excluding a competitive risk bias.

Keywords Cancer Cohort study Database study $\cdot$ Human insulin · Insulin glargine · Sulfonylureas · Type 2 diabetes
Abbreviations
ALD Affection de Longue Durée, chronic disease justifying full healthcare coverage
ATC Anatomical Therapeutic Chemical classification of medicines (WHO) 
EGB Echantillon Généraliste de Bénéficiaires: random 1/97 permanent sample of the French national healthcare insurance system database

IPR Insulin possession rate

PR Possession rate

\section{Introduction}

The question of a possible increased risk of cancer, especially breast cancer, in users of the insulin analogue, glargine (A21Gly, B31Arg, B32Arg human insulin), was raised following the publication of experimental data showing a higher affinity of insulin glargine for IGF1 receptors and signalling pathways, and a pro-angiogenic effect [1-5], with possible promoting and anti-apoptotic effects on human breast cancer cells [6]. Epidemiological studies also found an increased dose-dependent relative risk of cancer in exclusive users of insulin glargine [7, 8]. This excess risk of cancer was not confirmed in meta-analyses of short-term clinical trials [9] or in a long-term open trial [10] or in other epidemiological studies $[11,12]$. A re-analysis of the database that provided one of the initial signals confirmed the initial signal, but was unable to reproduce it in later years [13]. There has been much discussion of the real meaning of these findings [14, 15], the relative role of insulin itself or its analogues in the increased risk of cancer [16-18], the role of diabetes and hyperglycaemia as such $[19,20]$, or even of the reality of an increased risk of cancer in insulin users [21-23].

Because of these uncertainties, and notwithstanding an on-going risk management programme [24], we explored the Echantillon Généraliste de Bénéficiaires: random 1/97 permanent sample of the French national healthcare insurance system database (EGB) [25] to test for a possible association between the dispensing of insulin glargine and the occurrence of cancer. Since increased mortality rates might hide an increased risk of cancer, the combined outcome of death or cancer was also studied. We also tested a possible effect of increasing exposure to insulin, sulfonylureas and metformin on the event rates for cancer.

\section{Methods}

Data source This was a cohort study in the EGB, which is a permanent random sample of the French national healthcare insurance system database that covers approximately $90 \%$ of the French population [25].

The EGB includes basic demographic data and has prospectively collected all reimbursed medical expenses since 2002. In the mandatory French national healthcare system, the vast majority of prescribed medications for any indication or any duration are reimbursed with variable co-payment schemes, usually $15 \%, 35 \%, 65 \%$ or $100 \%$ coverage by the national healthcare insurance. The EGB contains data on all reimbursed medicines at whatever co-payment level, including dates of prescription, dispensing and preparation, and quantities dispensed. This information is captured automatically at the time of drug dispensing by the pharmacy or, when a medical or other procedure is done, at the end of a consultation.

In the French healthcare system, 31 major chronic diseases, including diabetes and cancer, have been designated by the healthcare insurance as 'Affection de Longue Durée' (ALD), i.e. chronic disease, and result in full insurance cover of all medical and pharmaceutical expenses related to the disease. Registration for one of these chronic diseases is proposed by the treating physician and confirmed by the healthcare insurance system physicians, based on the clinical information provided by the treating physician and, if necessary, by physical examination. The information recorded includes the chronic disease code, the associated International Classification of Diseases (ICD)-10 codes (www.who.int/classifications/icd/en/) and the date of first registration for the ALD. There is no diagnostic information on non-ALD acute disorders, but all medical interventions and prescribed medicines are included in the database, whatever the indication, allowing for some proxy assessment of such conditions. Most conditions that are included in the Charlson index (e.g. myocardial infarction, stroke) are either directly included as diagnostic codes or can be derived from the prescriptions. The EGB also includes the date of death, but not its cause.

Study populations The study population was all adult patients ( $\geq 18$ years) who had at least two prescriptions for insulin dispensed between 1 January 2003 and 31 December 2009 and were without cancer diagnosis at the time of dispensing the first insulin prescription or had not died in the month after dispensing of the first insulin prescription, and who had not had more than 1 year without claims in the database after dispensing of the first insulin prescription. Exclusive users were those who had received only insulin glargine or the same human insulin (mostly NPH-type basal insulin) between the first and last dispensing of prescriptions for insulin. Predominant users were those who had at least 12 prescriptions for insulin dispensed, with at least $80 \%$ of the exposure time on the same insulin; this group also includes exclusive users. Incident users were patients for whom at least 6 months of data prior to the first dispensing of a prescription for any insulin were available. Based on the above, four populations were defined: (1) incident exclusive users; (2) incident predominant users; (3) all exclusive users; and (4) all predominant users. Numbers of patients for these groups are given in Fig. 1. Each population was 
Fig. 1 Patient group selection. ${ }^{a}$ Exclusive users were patients who used only the same type of insulin throughout the study period; predominant users were users with at least $80 \%$ prescriptions for the insulin of interest. Only exclusive or predominant insulin glargine and human insulin users were included in the study

\begin{tabular}{|c|c|c|c|c|}
\hline \multicolumn{5}{|c|}{$\begin{array}{l}\text { Patients with } \geq 1 \text { insulin prescription between } 1 \text { January } 2003 \text { and } 31 \text { December } 2009 \\
\qquad N=8,485\end{array}$} \\
\hline & \multicolumn{3}{|c|}{$\begin{array}{l}\text { - } \quad<18 \text { years old } \\
\text { - } \quad<2 \text { insulin prescriptions before } 30 \text { June } 2010 \\
\text { - Cancer diagnosis before dispensing of first insulin prescription } \\
\text { - } \text { Death in the month after dispensing of first insulin prescription } \\
\text { - } \geq 1 \text { year without claims after dispensing of insulin prescription }\end{array}$} & $\begin{array}{ll}n=234 & (2.8 \%) \\
n=923 & (10.9 \%) \\
n=594 & (7.0 \%) \\
n=6 \quad(0.1 \%) \\
n=79 & (1.0 \%)\end{array}$ \\
\hline \multicolumn{2}{|c|}{$\begin{array}{l}\begin{array}{c}\text { Source population } \\
\text { classified according } \\
\text { to first insulin prescription } \\
n=6,649\end{array} \\
\end{array}$} & $\begin{array}{ll}\text { - } & \text { Insulin glargine (IG) } \\
\text { - } & \text { Human insulin (HI) } \\
\text { - } & \text { Other insulin analogue } \\
\text { - } & \text { Insulin association } \\
\end{array}$ & \multicolumn{2}{|c|}{$\begin{array}{l}n=1,536(23.1 \%) \\
n=2,510(37.7 \%) \\
n=1,234(18.6 \%) \\
n=1,369(20.6 \%)\end{array}$} \\
\hline $\begin{array}{l}\text { All predominant }{ }^{\mathrm{a}} \text { users } \\
\text { (type } 1 \text { and } 2 \text { diabetic) }\end{array}$ & $\begin{array}{l}\text { IG } n=1,174 \\
\text { HI } n=943\end{array}$ & \multicolumn{2}{|c|}{$\begin{array}{l}\text { All exclusive }{ }^{\mathrm{a}} \text { users } \\
\text { (type } 1 \text { and } 2 \text { diabetic) }\end{array}$} & $\begin{array}{l}\text { IG } n=1,011 \\
\text { HI } n=804\end{array}$ \\
\hline $\begin{array}{l}\text { All predominant }{ }^{\mathrm{a}} \text { users } \\
\text { (type } 2 \text { diabetic) }\end{array}$ & $\begin{array}{l}\text { IG } n=1,140 \\
\text { HI } n=703\end{array}$ & \multicolumn{2}{|c|}{$\begin{array}{l}\text { All exclusive }{ }^{\mathrm{a}} \text { users } \\
\text { (type } 2 \text { diabetic) }\end{array}$} & $\begin{array}{l}\text { IG } n=979 \\
\text { HI } n=586\end{array}$ \\
\hline $\begin{array}{l}\text { Incident predominant }{ }^{\mathrm{a}} \\
\text { users (type } 2 \text { diabetic) }\end{array}$ & $\begin{array}{l}\text { IG } n=1,049 \\
\text { HI } n=318\end{array}$ & \multicolumn{2}{|c|}{$\begin{array}{l}\text { Incident exclusive users } \\
\text { (type } 2 \text { diabetic) }\end{array}$} & $\begin{array}{l}\text { IG } n=927 \\
\text { HI } n=272\end{array}$ \\
\hline
\end{tabular}

included in the next one, representing increasingly larger populations, with the most restricted being incident exclusive and the largest being all predominant. The primary hypothesis was tested in the most restricted population, i.e. in incident exclusive users. The other populations were used for sensitivity analyses.

Study and exposure periods The study period was from 1 January 2003 to 30 June 2010 . The index date was the time of dispensing the first insulin prescription identified in the database. The exposure period was defined as the time from first dispensing of insulin to 28 days after the date of last dispensing, thus taking into account the usual duration of a dispensing for chronic treatment in France. Follow-up was censured to 30 June 2010. There was at least 6 months of follow-up for all patients included.

Outcomes Outcomes of interest were the first occurrence of a registration for cancer or occurrence of death during the follow-up. The type of cancer was recorded, but not the cause of death.

The pre-specified study hypothesis was that there would be an excess of cancer diagnoses in the population of incident exclusive users of insulin glargine compared with incident exclusive users of human insulin. The other populations (all users, predominant users) were used as sensitivity analyses, progressively increasing the numbers of patients and events.

Increasing risk of cancer diagnoses with increasing exposure to insulin or sulfonylureas $[26,27]$ and reduced risk with biguanides [28] were secondary hypotheses.
Because death rates in this population are high and death might be due to a concurrent risk, we also tested the HRs of death or cancer, with the hypothesis that a higher death rate might mask an imbalance in the risk of cancer.

Statistical analysis To estimate the probability of receiving insulin glargine or human insulin, a propensity score was constructed using logistic regression with the following baseline characteristics: sex, age at first dispensing of insulin, incident user or not, type 1 or 2 diabetes, date of long-term disease inscription for diabetes, four categories of chronic diseases with $100 \%$ coverage (severe hypertension, cardiovascular diseases, psychiatric disorders, other diseases) and the number of systemic drug dispensing according to the first level of the Anatomical Therapeutic Chemical classification of medicines (WHO) (ATC) for 6 months before the first dispensing of insulin for incident users and for the first 6 months in the database for the other patients. With regard to drug dispensing, some specific drug classes were included separately (e.g. oral glucose-lowering drugs and lipidlowering agents, to distinguish them from other cardiovascular drugs, or vaccines, to distinguish them from other antiinfective drugs).

The treatment or medication possession rate (PR) was defined by the ratio of the number of treatments dispensed during the insulin exposure period divided by the number of 28 day periods during the follow-up period. This was computed for insulin, biguanide, sulfonylureas and other oral glucose-lowering treatments, as an indicator of the intensity of drug exposure. 
Survival analyses were conducted using proportional hazards Cox models. For each outcome (cancer, cancer or death), the HR and its $95 \%$ CI associated with exposure to insulin glargine compared with human insulin was estimated in the four populations defined above. Propensity scores were tested separately as an adjustment covariate and a quartile stratifying covariate. Other covariates used for adjustment were the insulin PR, the biguanide PR, the sulfonylurea PR and the PR for other oral glucoselowering treatments. The proportionality of risks was verified. In addition, crude Kaplan-Meier survival curves were drawn.

\section{Results}

Patient group selection and the analysis cohorts are shown in Fig. 1. Of 8,485 patients with a first dispensing of insulin, 6,649 were initially included. Because in incident type 1 diabetic patients there was no case of cancer in those exposed to insulin glargine and only one in those exposed to human insulin, further analyses were restricted to type 2 diabetic patients. Of these type 2 diabetic patients, 1,199 were incident exclusive users (most restrictive population) and 1,843 were all predominant users (largest group). Baseline insulin glargine and human insulin patient characteristics were very similar from the most restrictive to the more extensive populations (Tables 1 and 2), even though the population size, which did not change much with insulin glargine (from 927 to 1,140 patients), almost tripled with human insulin (from 272 to 703 subjects). Patients on insulin glargine or human insulin had the same age within a year or two. More men were on insulin glargine $(50 \%)$ than on human insulin $(40 \%)$. Patients on insulin glargine had more concomitant diseases and medications (Table 1). More than $70 \%$ of patients on human insulin were exposed only to NPH insulin, with $30 \%$ exposed to premix insulins combining intermediate and fast-acting insulins.

Exposures varied from 2,273 to 3,125 patient-years for insulin glargine and from 614 to 2,340 patient-years for human insulin. Cancer was reported in 18.0 (95\% CI 12.5, 23.6) and 22.8 (95\% CI 10.9, 34.7) per 1,000 patient-years in exclusive users of insulin glargine and human insulin, respectively (Table 2), and in 14.7 (95\% CI 10.5, 19.0) and 24.3 (95\% CI 18.0, 30.7) per 1,000 patient-years in all predominant insulin glargine and human insulin patients.

The main study endpoint, the HR for diagnoses of cancer with insulin glargine compared with human insulin in incident exclusive users, was 0.59 (95\% CI $0.28,1.25)$. This value for all predominant users was 0.58 (95\% CI 0.34 , 1.01; Table 2). The results were the same, regardless of whether the propensity score was used as a continuous adjustment variable or as a stratifying variable. Kaplan-
Meier all-cause cancer-free crude survival curves were very similar, parallel or superimposed (not shown).

There was no significant difference in the event rates for the more common types of cancer. More specifically, in all population groups there were numerically more cases and higher event rates for breast cancers in users of human insulin than in users of insulin glargine (Table 3).

For the secondary endpoints, the occurrence of cancer diagnoses was associated with increasing insulin exposure as assessed by the PR, ranging for insulin possession rate (IPR) $80 \%$ to $100 \%$ vs $0 \%$ to $20 \%$ from 2.14 (95\% CI 0.97 , $4.72)$ in the incident exclusive population to 2.26 (95\% CI $1.26,4.06$ ) in all predominant users (Table 2). Cancer diagnoses were also associated with exposure to sulfonylureas for all populations, ranging for PR $80 \%$ to $100 \%$ vs $0 \%$ to $20 \%$ from $2.30(95 \%$ CI $1.17,4.54)$ for incident exclusive patients to $2.28(95 \%$ CI $1.38,3.76)$ for all predominant patients (Table 2 ). Although exposure to biguanide was generally associated with an HR below 1 , this never reached significance and did not show clear exposure-dependence (Table 2).

Death or cancer was reported in 22.4 (95\% CI 16.3, 28.6) per thousand patient-years for incident exclusive users of insulin glargine and in 45.6 (95\% CI 28.7, 62.5) per thousand patient-years for users of human insulin. The HR for all-cause death or cancer with insulin glargine compared with human insulin, stratified by the propensity score and adjusted for drug possession ratios, varied from $0.58(95 \%$ CI $0.32,1.06)$ in incident exclusive users to $0.56(95 \%$ CI $0.36,0.87$ ) in all predominant patients. The hypothesis of a concurrent risk of death masking the risk of cancer in insulin glargine patients was thus not verified. Risk of cancer or death was also increased in the higher stratum of the IPR ( $80 \%$ to $100 \%$ vs $0 \%$ to $20 \%$ ), ranging from adjusted HR $2.94(95 \%$ CI $1.52,5.68)$ in incident exclusive users to 2.82 $(95 \%$ CI $1.75,4.55)$ in all predominant users. A moderately increased risk of cancer or death in the higher stratum of sulfonylurea exposure was also found; it ranged from HR $1.62(95 \%$ CI $0.89,2.94)$ in exclusive incident users to 1.87 $(95 \%$ CI $1.22,2.87)$ in all predominant users.

\section{Discussion}

In this random sample of the national healthcare insurance reimbursement database, we found that the dispensing of insulin glargine alone was not associated with an increased risk of subsequent cancer diagnoses compared with human insulin alone. Our analysis used multivariate Cox analysis stratified for propensity scores and exposure to glucoselowering drugs. The upper limit of the $95 \%$ CI of this HR was lower than the HR reported in previous studies [7, 8], allowing us to confidently rule out the possibility that 
Table 1 Baseline characteristics of incident type 2 diabetic patients exposed to insulin glargine or human insulin as indicated
${ }^{a}$ Number of prescriptions for insulin dispensed during the 6 months prior to index date (incident patients) or during the 6 months after inclusion in the database (non-incident patients) for insulin dispensation; classifications are by ATC

${ }^{\mathrm{b}}$ Proportion of prescriptions for insulin dispensed during exposure period to total number of possible prescriptions for insulin

\begin{tabular}{|c|c|c|c|c|}
\hline \multirow[t]{2}{*}{ Characteristic } & \multicolumn{2}{|c|}{ Exclusive incident users } & \multicolumn{2}{|c|}{ All predominant users } \\
\hline & $\begin{array}{l}\text { Insulin } \\
\text { glargine }\end{array}$ & $\begin{array}{l}\text { Human } \\
\text { insulin }\end{array}$ & $\begin{array}{l}\text { Insulin } \\
\text { glargine }\end{array}$ & $\begin{array}{l}\text { Human } \\
\text { insulin }\end{array}$ \\
\hline$n$ & 927 & 272 & 1,140 & 703 \\
\hline Male sex, $n(\%)$ & $467(50.4)$ & $108(39.7)$ & $575(50.4)$ & $291(41.4)$ \\
\hline Age at first dispensing of insulin, mean (SD) & $68.1(13.3)$ & $69.7(15.2)$ & $67.8(13.2)$ & $69.9(13.6)$ \\
\hline \multicolumn{5}{|l|}{ Long-term disease inscription for diabetes, $n(\%)$} \\
\hline Before 1995 & $156(16.8)$ & $74(27.2)$ & $216(18.9)$ & $284(40.4)$ \\
\hline 1995-1999 & $194(20.9)$ & $41(15.1)$ & $245(21.5)$ & $136(19.3)$ \\
\hline $2000-2004$ & $441(47.6)$ & $123(45.2)$ & $513(45.0)$ & $243(34.6)$ \\
\hline 2005-2009 & $136(14.7)$ & $34(12.5)$ & $166(14.6)$ & $40(5.7)$ \\
\hline \multicolumn{5}{|l|}{ At least one diagnosis of long-term disease, $n(\%)$} \\
\hline Severe hypertension & $148(16.0)$ & $32(11.8)$ & $171(15.0)$ & $66(9.4)$ \\
\hline Cardiovascular diseases & $139(15.0)$ & $45(16.5)$ & $173(15.2)$ & $93(13.2)$ \\
\hline Psychiatric disorders & $59(6.4)$ & $14(5.1)$ & $62(5.4)$ & $27(3.8)$ \\
\hline Other diseases & $202(21.8)$ & $63(23.2)$ & $247(21.7)$ & $125(17.8)$ \\
\hline \multicolumn{5}{|l|}{ Systemic drug dispensing, mean (SD) } \\
\hline A10, oral glucose-lowering & $9.5(5.8)$ & $4.5(4.9)$ & $9.4(5.9)$ & $4.5(5.2)$ \\
\hline Other A, gastrointestinal tract/metabolism & $3.4(4.5)$ & $2.8(4.0)$ & $3.3(4.5)$ & $2.9(4.2)$ \\
\hline $\mathrm{B}$, blood and blood forming organs & $2.8(3.6)$ & $2.2(3.1)$ & $2.9(3.6)$ & $2.7(3.5)$ \\
\hline C10, lipid-modifying agents & $2.8(3.0)$ & $1.5(2.4)$ & $2.9(3.0)$ & $2.0(2.8)$ \\
\hline Other $\mathrm{C}$, cardiovascular system & $11.7(10.1)$ & $9.0(8.8)$ & $11.7(10.0)$ & $11.8(10.0)$ \\
\hline $\mathrm{G}$, genito-urinary system & $0.8(2.0)$ & $0.4(1.3)$ & $0.7(2.0)$ & $0.5(1.7)$ \\
\hline $\mathrm{H}$, endocrine system & $0.9(2.1)$ & $0.8(1.8)$ & $0.9(2.1)$ & $0.6(1.7)$ \\
\hline $\mathrm{J} 07$, vaccines & $0.4(0.5)$ & $0.2(0.5)$ & $0.3(0.5)$ & $0.2(0.4)$ \\
\hline Other $\mathrm{J}$, anti-infectives for systemic use & $0.8(1.3)$ & $0.8(1.4)$ & $0.8(1.3)$ & $0.7(1.3)$ \\
\hline $\mathrm{L}$, anti-neoplastic and immunomodulating agents & $0.1(0.5)$ & $0.1(0.5)$ & $0.1(0.6)$ & $0.1(0.5)$ \\
\hline $\mathrm{M}$, muscles, bones and joints & $1.4(2.7)$ & $1.0(2.1)$ & $1.4(2.7)$ & $1.1(2.3)$ \\
\hline N01-N02, analgesics-anaesthetics & $2.7(3.3)$ & $2.1(2.4)$ & $2.7(3.3)$ & $2.5(2.9)$ \\
\hline Other $\mathrm{N}$, brain and nervous system & $4.2(6.7)$ & $3.3(5.6)$ & $4.0(6.4)$ & $4.0(6.1)$ \\
\hline $\mathrm{P}$, anti-parasitic products & $0.0(0.2)$ & $0.0(0.1)$ & $0.0(0.2)$ & $0.0(0.1)$ \\
\hline $\mathrm{R}$, respiratory system & $1.7(4.1)$ & $1.3(3.3)$ & $1.6(3.9)$ & $1.5(3.7)$ \\
\hline S, sensory organs & $1.0(2.7)$ & $0.7(2.3)$ & $1.1(2.8)$ & $1.1(3.3)$ \\
\hline \multicolumn{5}{|l|}{$\mathrm{PR}^{\mathrm{b}}$, mean $(\mathrm{SD})$} \\
\hline Insulin & $57.9(23.4)$ & $65.0(24.8)$ & $58.4(22.9)$ & $65.1(23.2)$ \\
\hline Biguanide & $41.8(41.2)$ & $17.1(32.6)$ & $41.8(40.8)$ & $20.9(35.3)$ \\
\hline Sulfonylurea & $36.8(40.8)$ & $15.3(30.9)$ & $35.7(40.2)$ & $17.4(32.1)$ \\
\hline Other oral glucose-lowering agents & $26.8(37.3)$ & $8.4(24.3)$ & $26.9(36.9)$ & $10.7(26.3)$ \\
\hline
\end{tabular}

results of those previous studies were reproduced in this representative sample of the French population.

We detected an association of increasing mean PR for any insulin and for sulfonylureas with the risk of cancer, adding weight to the hypothesis that increased risk of cancer is associated with increased insulin exposure, whether exogenous or stimulated.

Various sensitivity analyses, including patients with at least $80 \%$ of exposure time on the same insulin, or including only incident (previously untreated with insulin for at least 6 months) or all patients treated with insulin, reached the same conclusion with little variation in the point estimates for the HRs. There was little difference between crude and adjusted risk ratios.

The main hypothesis for this study was based on the studies that appeared in 2009 in Diabetologia [7, 8, 11, 29] and were the source of much controversy [30]. These studies found that the incidence of cancer seemed greater in patients dispensed only insulin glargine than in patients dispensed only human insulin. They also found no overall difference between different insulin types, but post-hoc analyses found an increased risk of cancer, especially of the breast, in 
Table 2 Hazard ratios from multivariate Cox proportional hazards models for diagnosis of cancer in patients with type 2 diabetes exposed to insulin glargine or human insulin, stratified by propensity score quartiles users as indicated

\begin{tabular}{|c|c|c|c|c|}
\hline \multirow[t]{2}{*}{ Variable } & \multicolumn{2}{|l|}{ Incident users } & \multicolumn{2}{|l|}{ All users } \\
\hline & Exclusive & Predominant & Exclusive & Predominant \\
\hline \multicolumn{5}{|c|}{ Number of patient-years exposure } \\
\hline Human insulin & 614.2 & 820.5 & $1,705.4$ & $2,341.0$ \\
\hline Insulin glargine & $2,272.8$ & $2,800.3$ & $2,342.1$ & $3,125.1$ \\
\hline \multicolumn{5}{|l|}{ Number of cases of cancer } \\
\hline Human insulin $(n)$ & 14 & 17 & 54 & 57 \\
\hline Insulin glargine $(n)$ & 41 & 44 & 42 & 46 \\
\hline \multicolumn{5}{|c|}{ Cancer incidence per 1,000 person-years, HR $(95 \% \mathrm{CI})$} \\
\hline Human insulin & $22.8(10.9,34.7)$ & $20.7(10.9,30.6)$ & $31.7(23.2,40.1)$ & $24.3(18.0,30.7)$ \\
\hline Insulin glargine & $18.0(12.5,23.6)$ & $15.7(11.1,20.4)$ & $17.9(12.5,23.4)$ & $14.7(10.5,19.0)$ \\
\hline \multicolumn{5}{|l|}{ Crude HR (95\% CI) } \\
\hline Human insulin & 1.0 & 1.0 & 1.0 & 1.0 \\
\hline Insulin glargine & $0.80(0.44,1.47)$ & $0.76(0.43,1.33)$ & $0.53(0.35,0.80)$ & $0.57(0.39,0.84)$ \\
\hline \multicolumn{5}{|l|}{ Adjusted HR (95\% CI) } \\
\hline Human insulin & 1.0 & 1.0 & 1.0 & 1.0 \\
\hline Insulin glargine & $0.59(0.28,1.25)$ & $0.60(0.31,1.18)$ & $0.61(0.32,1.18)$ & $0.58(0.34,1.01)$ \\
\hline $\begin{array}{l}\text { New long-term disease } \\
\text { after initiation of insulin } \\
\text { IPR }\end{array}$ & $1.08(0.50,2.33)$ & $1.03(0.50,2.12)$ & $0.66(0.35,1.25)$ & $0.78(0.43,1.40)$ \\
\hline $0-39 \%$ & 1.0 & 1.0 & 1.0 & 1.0 \\
\hline $40-59 \%$ & $1.12(0.51,2.48)$ & $1.14(0.53,2.45)$ & $1.03(0.53,2.00)$ & $1.10(0.58,2.07)$ \\
\hline $60-79 \%$ & $1.75(0.82,3.73)$ & $1.63(0.78,3.38)$ & $1.51(0.82,2.80)$ & $1.47(0.81,2.68)$ \\
\hline $80-100 \%$ & $2.14(0.97,4.72)$ & $2.05(0.95,4.45)$ & $2.33(1.28,4.22)$ & $2.26(1.26,4.06)$ \\
\hline \multicolumn{5}{|l|}{ Sulfonylureas PR } \\
\hline $0-19 \%$ & 1.0 & 1.0 & 1.0 & 1.0 \\
\hline $20-79 \%$ & $1.15(0.52,2.55)$ & $1.03(0.47,2.24)$ & $1.25(0.71,2.20)$ & $1.25(0.71,2.20)$ \\
\hline $80-100 \%$ & $2.30(1.17,4.54)$ & $2.69(1.42,5.09)$ & $1.98(1.17,3.35)$ & $2.28(1.38,3.76)$ \\
\hline \multicolumn{5}{|l|}{ Biguanides PR } \\
\hline $0-19 \%$ & 1.0 & 1.0 & 1.0 & 1.0 \\
\hline $20-79 \%$ & $0.51(0.21,1.21)$ & $0.52(0.23,1.16)$ & $0.48(0.23,1.00)$ & $0.49(0.24,0.98)$ \\
\hline $80-100 \%$ & $0.82(0.43,1.57)$ & $0.74(0.40,1.38)$ & $0.98(0.60,1.59)$ & $0.92(0.57,1.48)$ \\
\hline \multicolumn{5}{|c|}{ Other oral glucose-lowering agent PR } \\
\hline $0-19 \%$ & 1.0 & 1.0 & 1.0 & 1.0 \\
\hline $20-79 \%$ & $0.65(0.26,1.59)$ & $0.82(0.37,1.81)$ & $0.71(0.35,1.45)$ & $0.77(0.40,1.47)$ \\
\hline $80-100 \%$ & $1.04(0.46,2.34)$ & $1.04(0.46,2.33)$ & $1.08(0.59,1.98)$ & $1.05(0.57,1.92)$ \\
\hline
\end{tabular}

diabetic patients who were exposed only to insulin glargine $[7,8,11]$ compared with those exposed only to human insulin. Our findings did not reproduce these results. On the contrary, we can confidently rule out the possibility that the increased risk reported in those studies applied in our population. In all population groups studied, the point estimate of the HR for the risk of cancer with insulin glargine was below one. Our results are consistent with some of the experimental data [31]. Other studies have also found a similar point estimate around 0.80 for the risk of cancer with insulin glargine compared with human insulin [9, 29].
Similarly, we found no excess risk of breast cancer with insulin glargine.

Among the previously published studies, Hemkens et al. [7] reported an excess incidence of cancer only after adjusting for dose of insulin glargine. We were not able to adjust for dose, but did adjust for dispensing (PR) as a proxy for exposure. In doing so, we found that there was an increased risk of cancer with increased relative dispensing of insulin and that this was common to all insulins tested by us, with no interaction with the type of insulin. What might be thought unusual is that Hemkens et al. did not find a dose- 
Table 3 Event rates per thousand patient-years of follow-up for the more common cancer types in incident exclusive users and in all predominant users of insulin glargine or human insulin

\begin{tabular}{|c|c|c|c|c|c|c|c|c|}
\hline \multirow[t]{3}{*}{ Type of cancer } & \multicolumn{4}{|c|}{ Incident exclusive users } & \multicolumn{4}{|c|}{ All predominant users } \\
\hline & \multicolumn{2}{|c|}{ Insulin glargine $^{a}$} & \multicolumn{2}{|c|}{ Human insulin ${ }^{\mathrm{b}}$} & \multicolumn{2}{|c|}{ Insulin glargine ${ }^{c}$} & \multicolumn{2}{|c|}{ Human insulin $^{\mathrm{d}}$} \\
\hline & $n$ & $\begin{array}{l}\text { Event rate, \%o person- } \\
\text { years }(95 \% \mathrm{CI})\end{array}$ & $n$ & $\begin{array}{l}\text { Event rate, \%o person- } \\
\text { years }(95 \% \mathrm{CI})\end{array}$ & $n$ & $\begin{array}{l}\text { Event rate, \%o person- } \\
\text { years }(95 \% \mathrm{CI})\end{array}$ & $n$ & $\begin{array}{l}\text { Event rate, \%o person- } \\
\text { years }(95 \% \mathrm{CI}))\end{array}$ \\
\hline All cancers & 41 & $18.0(12.5,23.6)$ & 14 & $22.8(10.9,34.7)$ & 46 & $14.7(10.5,19.0)$ & 57 & $24.3(18.0,30.7)$ \\
\hline Prostate $^{\mathrm{e}}$ & 8 & $7.1(3.1,14.0)$ & 2 & $6.4(1.0,30.3)$ & 9 & $5.8(2.7,11.0)$ & 11 & $11.7(4.8,18.7)$ \\
\hline Lung & 6 & $2.6(1.0,5.7)$ & 1 & $1.6(0.0,0.1)$ & 6 & $1.9(0.7,4.2)$ & 5 & $2.1(0.7,5.0)$ \\
\hline Pancreas & 4 & $1.8(0.5,4.5)$ & 3 & $4.9(1.0,14.3)$ & 4 & $1.3(0.3,3.3)$ & 5 & $2.1(0.7,5.0)$ \\
\hline Breast ${ }^{f}$ & 2 & $1.7(0.2,6.3)$ & 3 & $8.0(1.7,23.4)$ & 2 & $1.3(0.2,4.6)$ & 8 & $5.7(2.5,11.2)$ \\
\hline Colorectal & 3 & $1.3(0.3,3.9)$ & 1 & $1.6(0.0,9.1)$ & 5 & $1.6(0.5,3.7)$ & 6 & $2.6(0.9,5.6)$ \\
\hline Bladder & 2 & $0.9(0.1,3.2)$ & 1 & $1.6(0.0,9.1)$ & 3 & $1.0(0.2,2.8)$ & 1 & $0.4(0.0,2.4)$ \\
\hline Liver, biliary duct & 2 & $0.9(0.1,3.2)$ & 1 & $1.6(0.0,9.1)$ & 2 & $0.6(0.1,2.3)$ & 2 & $0.9(0.1,3.1)$ \\
\hline
\end{tabular}

dependent risk for insulins other than insulin glargine [7]. Jonasson et al. [8] reported an excess incidence of breast cancer only, but not of all cancers or any other cancer. Further analyses of the same population over different time periods were unable to reproduce the increased risk found initially [13]. The findings of the SDRN Epidemiology Group were inconsistent across the different study designs, with some (but not all) study designs suggesting an excess of all cancer incidence and breast cancer [11]. We found no such increase in any of our study populations. In fact, we found a numerically lower rate of breast cancer in insulin glargine users than in human insulin users.

The explanation of why our findings do not confirm those of these previous studies might reside in possible biases, either in previous studies, or in the present study.

We can probably exclude most biases concerning case ascertainment or selection. In this reimbursement database, randomly selected patients from the national healthcare insurance databases are prospectively registered, and data are collected prospectively and independently of patients, prescribers or any pre-specified hypothesis. Our population is by design representative of the French population [25]. Registration for long-term diseases is mandatory for patients to receive full cover for healthcare expenditures related to the disease. Thus it is very unlikely that patients treated for cancer would not be registered to obtain full cover for this expensive disease. There is no reason for diagnoses of cancer to have been registered differently for patients treated with insulin glargine compared with those on human insulin.
It also seems unlikely that human insulin was channelled to higher cancer risk patients or insulin glargine to lowerrisk patients. The very small effect of the propensity score stratification on the results indicates that there were very small differences between the insulin user populations. Most of our patients were included in the database before the alerts on insulin glargine and cancer risk in 2009, which was, in fact, the end of the inclusion period. Following the notorious putative cancer risk alert for insulin glargine, any change in indication or reduction in the use of insulin glargine in patients suspected to be at higher risk of cancer would have appeared only in 2009, and would therefore have affected only a very small proportion of the patients. Increased awareness of a possible risk of cancer with insulin glargine might have increased detection of cancer in insulin glargine users, but again this would only have happened at the very end of the follow-up period. This potential detection bias might have explained a higher apparent risk of cancer in insulin glargine users, but this is not what we found. We adjusted for common confounders, such as age, duration of exposure and concomitant diseases. The latter include markers of increased risk of cancer, such as coronary heart disease or peripheral arterial disease, but these, too, were not less frequent in insulin glargine users than in human insulin users. We were unable to adjust for BMI or smoking, but there is no indication that these would be confounders modifying prescription patterns and resulting in a distorted apparent risk. BMI is associated with cancer and with type 2 diabetes [32-36], although it is unclear 
whether this association is independent or related to insulin resistance [37]. In other studies, there was no difference in mean BMI between different insulin groups in type 2 diabetic patients, and there is no medical reason to prefer one insulin over the other on the basis of BMI. We did not account for smoking, but any confounding would result from a preferential use of one or the other type of insulin in smokers or non-smokers, which seems unlikely. In addition, there was no indication of a different rate of lung cancer, or of diagnoses involving chronic lung disease or other proxies such as coronary heart disease. On the other hand, we confirmed the increased risk of cancer diagnoses with increasing use of insulin (any type) or increasing use of sulfonylureas in all population groups, a finding that supports the notion that insulin as such plays a cancer-promoting role, be it exogenously added or endogenously secreted upon stimulation [38]. We did not confirm the protective effect of biguanides [16], although the risk of cancer with biguanides was indeed lower than in sulfonylurea users.

The first conclusion of our study is therefore that we found no confirmation of the hypothesis that patients exposed only to insulin glargine have a higher risk of cancer (including breast cancer) than those exposed only to human insulin. On the contrary, we found fewer cancer diagnoses in insulin glargine than in human insulin users.

One explanation of our finding could be concurrent risk bias. Thus if patients treated with insulin glargine died sooner than patients on human insulin, they might be at less apparent risk of developing cancer. However, we found the opposite, namely that patients on insulin glargine tended to die less soon than patients on human insulin, a finding that in some cohorts reached significance. Again, the risk of ascertainment bias would be low, since registration of death comes from the census bureau and the pension funds, and is independent of treatment or use of healthcare resources. We have no indication as to whether the increased death rate is due to the insulin chosen, or to patient selection or channelling of human insulin to more severely ill patients than those on insulin glargine. Different death rates between insulin glargine and human insulin users have not been reported in clinical trials of insulin glargine, but patients randomised to insulin glargine had fewer episodes of hypoglycaemia, a condition that might predispose to earlier death [39]. The follow-up was short in the above trials. In actual practice, human insulin might have been chosen for tighter control of diabetes [40-42], which has also been associated with higher mortality rates [43]. Higher all-cause death rates might reduce the apparent risk of cancer in users of human insulin and could perhaps help explain findings in other epidemiological studies showing higher rates of cancer with insulin glargine or lower rates with comparators. None of the above studies reported on all-cause death or other competing risks. One retrospective study comparing use of bolus insulin analogues with bolus human insulin in hospital also found that the death rate in patients treated with human insulin was double that of patients given insulin analogues, results that are quantitatively not very different from ours, albeit in a very different setting [44].

Because our analysis of deaths was exploratory without any pre-formulated hypothesis, the exact role of the patient status or the choice of insulin remains to be determined. It would, therefore, be desirable to re-analyse clinical trials comparing analogues with human insulin for all-cause death rates and to verify our findings in other settings and other databases.

In conclusion, we did not confirm previous findings of an increased risk of cancer with insulin glargine compared with human insulin. We did, however, confirm the increased risk of cancer with higher insulin or sulfonylurea exposure. We also found an increased risk of all-cause death with human insulin compared with insulin glargine, a finding that certainly warrants further exploration.

Acknowledgements This study was performed at the request of the French Health Authorities. The data belong to the French National Health System and may be accessed for reanalysis on site. The study respects the principles of the European Network of Centres of Excellence in Pharmacoepidemiology and Pharmacovigilance Chart (www. encepp.eu). We would like to thank P. Robinson for reviewing the language of this paper.

Funding This study was supported by an unconditional grant from sanofi-aventis. The sponsor had no influence on study design, conduct, analysis or interpretation, or in the writing of this paper.

Duality of interest The Department of Pharmacology at Bordeaux University does studies of drug effectiveness and risks in real-life use with various study designs. Studies are done at the request of the regulatory authorities, or for their attention. Most of these studies are funded by pharmaceutical companies, including most manufacturers of insulin and other glucose-lowering products. In addition, we test traditional medicines from North Africa and Asia on experimental models of metabolic syndrome and type 2 diabetes. We also study the effectiveness and risks of drugs used to treat cancer (see www.pharmacoepi. eu). H. Gin and C. Le Jeunne are diabetologists and nutrition experts, and as such have performed clinical trials of glucose-lowering agents at the request of sanofi-aventis and other manufacturers.

Contribution statement $\mathrm{NM}, \mathrm{PB}$ and $\mathrm{AP}$ had the initial ideas and followed the scientific aspects of the study. RL, BA, MAB and AA extracted the data and performed all the analyses. CD-P and CD were study coordinators and contributed to all operational and scientific aspects, including study conception, design and implementation, and analysis. HG and CLJ are diabetologists who contributed to analytic strategies and the choice of patient models, and also to the interpretation of the results. All authors contributed to the scientific discussions on protocol writing, definition and interpretation of data, and also approved the final version of this paper. NM wrote the first draft of the paper, which all the other authors commented upon and approved. $\mathrm{NM}$ is the guarantor of the study. 
Open Access This article is distributed under the terms of the Creative Commons Attribution Noncommercial License which permits any noncommercial use, distribution, and reproduction in any medium, provided the original author(s) and source are credited.

\section{References}

1. Yehezkel E, Weinstein D, Simon M, Sarfstein R, Laron Z, Werner $H$ (2010) Long-acting insulin analogues elicit atypical signalling events mediated by the insulin receptor and insulin-like growth factor-I receptor. Diabetologia 53:2667-2675

2. Shukla A, Grisouard J, Ehemann V, Hermani A, Enzmann H, Mayer D (2009) Analysis of signaling pathways related to cell proliferation stimulated by insulin analogs in human mammary epithelial cell lines. Endocr Relat Cancer 16:429-441

3. Rensing KL, Houttuijn Bloemendaal FM, Weijers EM et al (2010) Could recombinant insulin compounds contribute to adenocarcinoma progression by stimulating local angiogenesis? Diabetologia 53:966-970

4. Le Roith D (2007) Insulin glargine and receptor-mediated signalling: clinical implications in treating type 2 diabetes. Diabetes Metab Res Rev 23:593-599

5. Kazda C, Slieker L, Ilag L, Byrd R, Rees T, Prince M (2010) Appraising the mitogenicity of insulin analogues relative to human insulin-response to: Weinstein D, Simon M, Yehezkel E, Laron Z, Werner H. Insulin analogues display IGF-I-like mitogenic and antiapoptotic activity in cultured cancer cells. Diabetes Metab Res Rev 2009; 25(1): 41-9. Diabetes Metab Res Rev 26:145-149

6. Teng JA, Hou RL, Li DL, Yang RP, Qin J (2011) Glargine promotes proliferation of breast adenocarcinoma cell line MCF-7 via AKT activation. Horm Metab Res 43:519-523

7. Hemkens LG, Grouven U, Bender R et al (2009) Risk of malignancies in patients with diabetes treated with human insulin or insulin analogues: a cohort study. Diabetologia 52:1732-1744

8. Jonasson JM, Ljung R, Talback M, Haglund B, Gudbjornsdottir S, Steineck G (2009) Insulin glargine use and short-term incidence of malignancies - a population-based follow-up study in Sweden. Diabetologia 52:1745-1754

9. Home PD, Lagarenne P (2009) Combined randomised controlled trial experience of malignancies in studies using insulin glargine. Diabetologia 52:2499-2506

10. Rosenstock J, Fonseca V, McGill JB et al (2009) Similar risk of malignancy with insulin glargine and neutral protamine Hagedorn $(\mathrm{NPH})$ insulin in patients with type 2 diabetes: findings from a 5 year randomised, open-label study. Diabetologia 52:1971-1973

11. Colhoun HM, SDRN Epidemiology Group (2009) Use of insulin glargine and cancer incidence in Scotland: a study from the Scottish Diabetes Research Network Epidemiology Group. Diabetologia 52:1755-1765

12. Suissa S, Azoulay L, Dell'aniello S, Evans M, Vora J, Pollak M (2011) Long-term effects of insulin glargine on the risk of breast cancer. Diabetologia 54:2254-2262

13. Ljung R, Talback M, Haglund B, Jonasson JM, Gudbjornsdottir S, Steineck G (2011) Insulin glargine use and short-term incidence of malignancies - a three-year population-based observation. Acta Oncol 50:685-693

14. Simon D, Balkau B (2010) Diabetes mellitus, hyperglycaemia and cancer. Diabetes Metab 36:182-191

15. Pocock SJ, Smeeth L (2009) Insulin glargine and malignancy: an unwarranted alarm. Lancet 374:511-513

16. Bowker SL, Yasui Y, Veugelers P, Johnson JA (2010) Glucoselowering agents and cancer mortality rates in type 2 diabetes: assessing effects of time-varying exposure. Diabetologia 53:1631-1637
17. Gallagher EJ, Fierz Y, Ferguson RD, Leroith D (2010) The pathway from diabetes and obesity to cancer, on the route to targeted therapy. Endocr Pract 16(5):864-873

18. Call R, Grimsley M, Cadwallader L et al (2010) Insulin-carcinogen or mitogen? Preclinical and clinical evidence from prostate, breast, pancreatic, and colorectal cancer research. Postgrad Med 122:158-165

19. Zhou XH, Qiao Q, Zethelius B et al (2010) Diabetes, prediabetes and cancer mortality. Diabetologia 53:1867-1876

20. Johnson JA, Bowker SL (2011) Intensive glycaemic control and cancer risk in type 2 diabetes: a meta-analysis of major trials. Diabetologia 54:25-31

21. Simon D (2010) Diabetes treatment with insulin glargine and risk of malignancy: methodological pitfalls and ethical issues. Diabetologia 53:204-205

22. Giovannucci E, Harlan DM, Archer MC et al (2010) Diabetes and cancer: a consensus report. CA Cancer J Clin 60:207-221

23. Johnson JA, Pollak M (2010) Insulin, glucose and the increased risk of cancer in patients with type 2 diabetes. Diabetologia 53:2086-2088

24. Grimaldi-Bensouda L, Marty M, Pollak M et al (2010) The international study of insulin and cancer. Lancet 376:769-770

25. Martin-Latry K, Begaud B (2010) Pharmacoepidemiological research using French reimbursement databases: yes we can! Pharmacoepidemiol Drug Saf 19:256-265

26. Monami M, Lamanna C, Balzi D, Marchionni N, Mannucci E (2009) Sulphonylureas and cancer: a case-control study. Acta Diabetol 46:279-284

27. Monami M, Lamanna C, Pala L et al (2008) Treatment with insulin secretagogues and cancer-related mortality in type 2 diabetic patients a retrospective cohort study. Exp Clin Endocrinol Diabetes 116:184-189

28. Monami M, Colombi C, Balzi D et al (2011) Metformin and cancer occurrence in insulin-treated type 2 diabetic patients. Diabetes Care 34:129-131

29. Currie CJ, Poole CD, Gale EA (2009) The influence of glucoselowering therapies on cancer risk in type 2 diabetes. Diabetologia 52:1766-1777

30. Hernandez-Diaz S, Adami HO (2010) Diabetes therapy and cancer risk: causal effects and other plausible explanations. Diabetologia 53:802-808

31. Erbel S, Reers C, Eckstein VW et al (2008) Proliferation of colo357 pancreatic carcinoma cells and survival of patients with pancreatic carcinoma are not altered by insulin glargine. Diabetes Care 31:1105-1111

32. Schienkiewitz A, Schulze MB, Hoffmann K, Kroke A, Boeing H (2006) Body mass index history and risk of type 2 diabetes: results from the European Prospective Investigation into Cancer and Nutrition (EPIC)-Potsdam Study. Am J Clin Nutr 84:427-433

33. Kubo A, Corley DA (2006) Body mass index and adenocarcinomas of the esophagus or gastric cardia: a systematic review and meta-analysis. Cancer Epidemiol Biomark Prev 15:872-878

34. Ahn J, Schatzkin A, Lacey JV Jr et al (2007) Adiposity, adult weight change, and postmenopausal breast cancer risk. Arch Intern Med 167:2091-2102

35. Larsson SC, Wolk A (2007) Obesity and colon and rectal cancer risk: a meta-analysis of prospective studies. Am J Clin Nutr 86:556-565

36. Renehan AG, Soerjomataram I, Tyson M et al (2010) Incident cancer burden attributable to excess body mass index in 30 European countries. Int J Cancer 126:692-702

37. Basen-Engquist K, Chang M (2011) Obesity and cancer risk: recent review and evidence. Curr Oncol Rep 13:71-76

38. Bowker SL, Majumdar SR, Veugelers P, Johnson JA (2006) Increased cancer-related mortality for patients with type 2 diabetes who use sulfonylureas or insulin. Diabetes Care 29:254-258

39. Dungan KM, Binkley P, Nagaraja HN, Schuster D, Osei K (2011) The effect of glycaemic control and glycaemic variability on mortality in patients hospitalized with congestive heart failure. Diabetes Metab Res Rev 27:85-93 
40. Mattila TK, de Boer A (2010) Influence of intensive versus conventional glucose control on microvascular and macrovascular complications in type 1 and 2 diabetes mellitus. Drugs 70:22292245

41. Marso SP, Kennedy KF, House JA, McGuire DK (2010) The effect of intensive glucose control on all-cause and cardiovascular mortality, myocardial infarction and stroke in persons with type 2 diabetes mellitus: a systematic review and meta-analysis. Diab Vasc Dis Res 7:119-130
42. Hill D, Fisher M (2010) The effect of intensive glycaemic control on cardiovascular outcomes. Diabetes Obes Metab 12:641-647

43. Group AS, Gerstein HC, Miller ME et al (2011) Long-term effects of intensive glucose lowering on cardiovascular outcomes. N Engl J Med 364:818-828

44. Ko KJ, Tomor V, Nathanson BH, Bouchard JR, Aagren M, Dubois RW (2010) Does type of bolus insulin matter in the hospital? Retrospective cohort analysis of outcomes between patients receiving analogue versus human insulin. Clin Ther 32:1954-1966 